\title{
Tensile properties of shielded metal arc welded ultrahigh hard armour steel joints
}

\author{
V. Balaguru 1, V. Balasubramanian ${ }^{2, *}$ and P. Shivkumar ${ }^{3}$ \\ ${ }^{1}$ Associate Director, Main Battle Tank Division (MBT), Combat Vehicles Research \& Development Establishment (CVRDE), \\ Defence Research \& Development Organization (DRDO), Avadi, Chennai, INDIA - 600054. \\ 2 Professor \& Director, Centre for Materials Joining and Research (CEMAJOR) Department of Manufacturing Engineering, \\ Annamalai University, Annamalainagar - (P.O), INDIA - 608002. \\ ${ }^{3}$ Former Director, Combat Vehicles Research \& Development Establishment (CVRDE), Defence Research \& Development \\ Organization (DRDO), Avadi, Chennai, INDIA - 600054.
}

Publication history: Received on 30 November 2020; revised on 06 December 2020; accepted on 20 December 2020

Article DOI: https://doi.org/10.30574/wjaets.2020.1.2.0029

\begin{abstract}
The present generation Armoured Tracked Vehicles (ATVs) are constructed using Rolled homogenized armour (RHA) grade steels closely confirming with AISI 4340 specifications. However, in future Armoured Tracked Vehicles (ATVs), the overall weight of ATVs has to be reduced enormously and hence, the designers have prescribed to employ Ultra High Hard Armour (UHA) steels for the construction. Welding is considered to be one of the important fabrication methods in ATVs construction. However, welding of UHA steels is highly challenging due to higher hardness and higher carbon content. Shielded Metal Arc Welding (SMAW) is among the most widely employed welding process in the construction of ATVs since it is more versatile and cost-effective. Armour grade steels are welded conventionally using Austenitic Stainless Steel (ASS) consumables to eliminate the serious problems of hydrogen induced cracking. Hence, in this investigation, an attempt has been made to study the influence of ASS welding consumables on tensile properties and hardness of UHA steel joints made by SMAW process. UHA steel plates having $15 \mathrm{~mm}$ thickness were welded by SMAW process using five different ASS consumables (having different $\mathrm{Cr}_{\mathrm{eq}} / \mathrm{Ni}_{\text {eq }}$ ratio). Tensile properties (unnotched and notched) of the welded joints were evaluated. From this investigation, it was observed that the joint welded using ASS consumable (having higher $\mathrm{Cr}_{\text {eq }} / \mathrm{Ni}_{\text {eq }}$ ratio) exhibited superior tensile properties as result of the evolution of ferrite phase with vermicular and globular morphology in the austenite matrix at weld metal region.
\end{abstract}

Keywords: Ultra high hard armour steel; Shielded metal arc welding; Austenitic stainless steel consumable; Tensile Properties; Microstructure

\section{Introduction}

Currently, armour steel plates, closely confirming with AISI 4340 specifications, are principally used in construction of Armored Tracked Vehicles (ATVs). These grade steels are employed in hull and turret structures of the ATVs. These grade steels are classified under high hardness (hardness is $>400 \mathrm{BHN}$ ) and high strength (yield strength is $>1100$ $\mathrm{MPa}$ ) steels category. These grade steels are difficult to weld due to high strength and high hardness. The problems normally encountered during welding of this steel are hydrogen induced cracking (HIC), heat affected zone (HAZ) softening [1]. However, they are welded, nowadays, using gas metal arc welding (GMAW), shielded metal arc welding (SMAW) and flux cored arc welding (FCAW) processes using austenitic and ferrite consumables. Though these grade steels are meeting all the requirements (as per the military standards) satisfactorily, the mobility of the fighting vehicles in all terrains is of significant importance due to higher overall weight of the vehicles. This concern is forcing the design engineers and fabrication engineers to think about reducing the overall weight of the futuristic ATVs.

\footnotetext{
${ }^{*}$ Corresponding author: Dr. V.Balasubramanian

Professor \& Director, Centre for Materials Joining and Research (CEMAJOR) Department of Manufacturing Engineering, Annamalai University, Annamalainagar - (P.O), INDIA - 608002.
} 
The development of Ultra High Hard (Hardness $\geq 570$ BHN) and Ultra High Strength (Yield Strength > 2200). Armour steel plates by controlling heat treatment methods and varying alloying elements paved way for the improvement in level of protection against the projectile attack on the ATVs. However, these grades of steel plates are used as frontal protection plates only in these vehicles [2]. Welding of these grade steels are challenging one due to the existence of higher carbon content (close to $0.47 \mathrm{wt} \%$ ) and higher carbon equivalent number (close to 0.8 ). These steels are more susceptible to hydrogen induced cracking and heat affected zone softening. HIC can occur at various positions in the weldment based on the degree of restraint and the elemental composition of base metal and weld metal. The ability of hydrogen to decrease the tensile properties of steel is well known. The evolvement of embrittlement, cold cracking and porosity related issues are associated with the dissolution of hydrogen in molten metal during welding [3].

The three methods of controlling HIC in Q\&T steel welds are: (i) temperature control method, (ii) isothermal transformation method and (iii) the utilization of austenitic stainless steel consumables. The method of temperature control relies on holding the welded joint at elevated temperature at which diffusion of hydrogen is accelerated. The method of isothermal transformation eliminates HIC by controlling the HAZ cooling rate so that it transforms to the softer non martensitic structure. Also it is not feasible to use the temperature of preheating greater than $150 \mathrm{oC}$ during welding of Q\&T steel. Hence the method of temperature control is highly limited and the method of isothermal transformation can therefore not be used in practical applications. The only option is to use welding consumables that virtually preclude the hydrogen being introduced in the HAZ and produce hydrogen-insensitive weld metal.

Madhusudhan Reddy et al.[4] studied the weldability of a high-strength low-alloy steel using different ASS fillers (188-6 and E 309L) and reported that the yield strength of 18-8-6 weld deposit was superior than that for the 309L. Madhusudhan Reddy et al., [5] investigated the susceptibility of low alloy steel to cold cracking using ASS and HNS fillers and reported that the HNS fillers offered better resistance to HIC than ASS fillers. This was attributed to the fact that there was no white phase formation as observed in the ASS weldment. Rao et al. [6] investigated the influence of welding processes on fatigue crack growth behaviour of low alloy high strength Q\&T steel cruciform joints fabricated using ASS consumables. Long streaks of $\delta$-ferrite in austenite matrix were found in case of SMA-weld metal which seemed to have lowered the resistance to the fatigue crack propagation. In case of FCA-weld metal, a discontinuous network of $\delta$-ferrite evolved in the austenitic matrix led to slower fatigue crack propagation.

An attempt was made by Magudeeswaran et al.,[7] to investigate the influence of welding consumables on tensile strength and ductility of high strength, Q\&T steel joints. ASS, LHF and HNS consumables had been employed to make the Q\&T steel joints by SMAW process. The results indicated that the joints produced using LHF steel electrodes revealed superior tensile properties than ASS and HNS electrode joints. The same authors [8] studied the effects of welding consumables to determine the dynamic fracture toughness of welded armour steel joints. For the welding of armourgrade Q\&T steels, ASS, LHF and high Ni steel consumables were employed. The usage of such consumables in the armour grade Q\&T steel welding contributed in the evolvement of different microstructures in the respective welds and has a great significant effect on the dynamic fracture toughness. It was found that the dynamic fracture toughness values of the joints made with high Ni steel consumables were superior to ASS and LHF joints [9].

Under blast loading, to illustrate the divergence in performance of fully penetrated (100\%) and partially penetrated (70\%) welds, a new explosion bulge test system was employed. The welded coupons include armour steel plate, Bisalloy BisPlate High Hardness Armour steel, joined to Bisalloy BisPlate80 steel employing an austenitic filler wire, TETRA S 20 93-G . Full-penetration welds were found to withstand, closer and greater blast loading without cracks than the partially penetrated welds [10].

The above literature review has revealed that the published technical papers in the area of welding of amour grade steels could be counted with fingers. Moreover, all these literatures are based on armour grade steels having yield strength $<1200 \mathrm{MPa}$ and hardness < $450 \mathrm{BHN}$. The existing information on UHA steels is very limited and hence the objective of this investigation is to evaluate the effect of ASS welding consumables (with various levels of $\mathrm{Cr}_{\text {eq }} / \mathrm{Ni}_{\text {eq }}$ ) on tensile properties of SMA welded UHA steel joints.

\section{Experimental}

The base metal (BM) used in this examination was $15 \mathrm{~mm}$ thick rolled UHA steel plates. The BM microstructure exhibits tempered martensite (Fig. 1). The plates were cut into the necessary dimensions $(300 \times 150 \mathrm{~mm})$ by abrasive cutter to configuration, as shown in Fig. 2, and welded the joints by SMAW process. The joint configuration was attained by using tack welding. The welding was done in the normal to the rolling direction. To avoid distortion necessary clamping was provided. Five ASS electrodes, having different chemical compositions, were used to weld the joints. The base metal chemical composition and welding electrodes are denoted in Table 1 . The $\mathrm{Cr}_{\text {eq }}$ and $\mathrm{Ni}_{\text {eq }}$ calculated for each electrode and 
the values are given in Table 2 along with joint notations. The important parameters for welding are published in Table 3.

Table 1 Chemical composition (wt \%) of base metal and welding electrodes (all weld metal) used in this investigation.

\begin{tabular}{|l|l|l|l|l|l|l|l|l|l|l|}
\hline Material & $\mathbf{C}$ & $\mathbf{S i}$ & $\mathbf{M n}$ & $\mathbf{C r}$ & $\mathbf{M o}$ & $\mathbf{N i}$ & $\mathbf{P}$ & $\mathbf{S}$ & $\mathbf{C u}$ & $\mathbf{F e}$ \\
\hline Base Metal & 0.315 & 0.239 & 0.54 & 1.25 & 0.52 & 1.25 & 0.018 & 0.009 & - & Bal \\
\hline E310-16 & 0.105 & 0.441 & 2.009 & 27.63 & 0.141 & 20.31 & 0.026 & 0.008 & 0.233 & Bal \\
\hline E307-16 & 0.049 & 0.544 & 5.502 & 19.43 & 0.151 & 9.259 & 0.025 & 0.004 & 0.211 & Bal \\
\hline E309-16 & 0.042 & 0.616 & 1.672 & 23.27 & 0.171 & 12.53 & 0.019 & 0.005 & 0.159 & Bal \\
\hline E308-16 & 0.026 & 0.905 & 1.10 & 19 & 0.145 & 9.412 & 0.027 & 0.011 & 0.188 & Bal \\
\hline E307-26 & 0.060 & 0.560 & 1.20 & 20.89 & 2.380 & 9.020 & 0.024 & 0.012 & 0.251 & Bal \\
\hline
\end{tabular}

Table 2 Joint Notations and $\mathrm{Cr}_{\mathrm{eq}}$ and $\mathrm{Ni}_{\mathrm{eq}}$ Values of Welding Electrodes

\begin{tabular}{|l|l|l|l|l|}
\hline Electrode Specification & Joint Notation & $\mathbf{C r}_{\mathbf{e q}}$ & $\mathbf{N i}_{\mathbf{e q}}$ & $\mathbf{C r}_{\mathbf{e q}} / \mathbf{N i} \mathbf{i q}_{\mathbf{e q}}$ \\
\hline AWS E310-16 & ASS1 & 28.43 & 24.46 & 1.16 \\
\hline AWS E307-16 & ASS2 & 20.42 & 13.48 & 1.51 \\
\hline AWS E309-16 & ASS3 & 24.46 & 14.63 & 1.67 \\
\hline AWS E308-16 & ASS4 & 20.50 & 10.74 & 1.90 \\
\hline AWS E307-26 & ASS5 & 24.11 & 11.42 & 2.11 \\
\hline
\end{tabular}

Table 3 Process Parameters used to weld the joints

\begin{tabular}{|c|c|c|c|c|c|c|}
\hline Parameters & Unit & ASS1 & ASS2 & ASS3 & ASS4 & ASS5 \\
\hline Electrode specification & AWS E & $310-16$ & $307-106$ & $309-16$ & $308 \mathrm{~L}-16$ & $307-26$ \\
\hline Electrode polarity & -- & DCEP & DCEP & DCEP & DCEP & DCEP \\
\hline Welding position & -- & $1 \mathrm{G}$ & $1 \mathrm{G}$ & $1 \mathrm{G}$ & $1 \mathrm{G}$ & $1 \mathrm{G}$ \\
\hline Preheat temperature & ${ }^{\circ} \mathrm{C}$ & 200 & 200 & 200 & 200 & 200 \\
\hline Interpass temperature & ${ }^{\circ} \mathrm{C}$ & 150 & 150 & 150 & 150 & 150 \\
\hline Electrode baking temp & ${ }^{\circ} \mathrm{C}$ & 200 & 200 & 200 & 200 & 200 \\
\hline \multicolumn{7}{|l|}{ For Root Pass Welding } \\
\hline Electrode diameter & $\mathrm{Mm}$ & 3.16 & 3.16 & 3.16 & 3.16 & 3.16 \\
\hline Welding current & A & 90 & 90 & 90 & 90 & 90 \\
\hline Arc voltage & Volts & 24 & 24 & 24 & 24 & 24 \\
\hline Welding Speed & $\mathrm{mm} / \mathrm{min}$ & 250 & 250 & 245 & 240 & 235 \\
\hline \multicolumn{7}{|l|}{ For Filling Pass Welding } \\
\hline Electrode diameter & $\mathrm{Mm}$ & 4 & 4 & 4 & 4 & 4 \\
\hline Welding current & A & 132 & 142 & 148 & 145 & 130 \\
\hline Arc voltage & $\mathrm{V}$ & 23 & 23 & 23 & 23 & 23 \\
\hline Welding speed & $\mathrm{mm} / \mathrm{min}$ & 270 & 265 & 275 & 260 & 285 \\
\hline Average heat input/pass & $\mathrm{kJ} \mathrm{mm} \mathrm{m}^{-1}$ & 0.92 & 0.95 & 0.96 & 0.98 & 1.02 \\
\hline
\end{tabular}




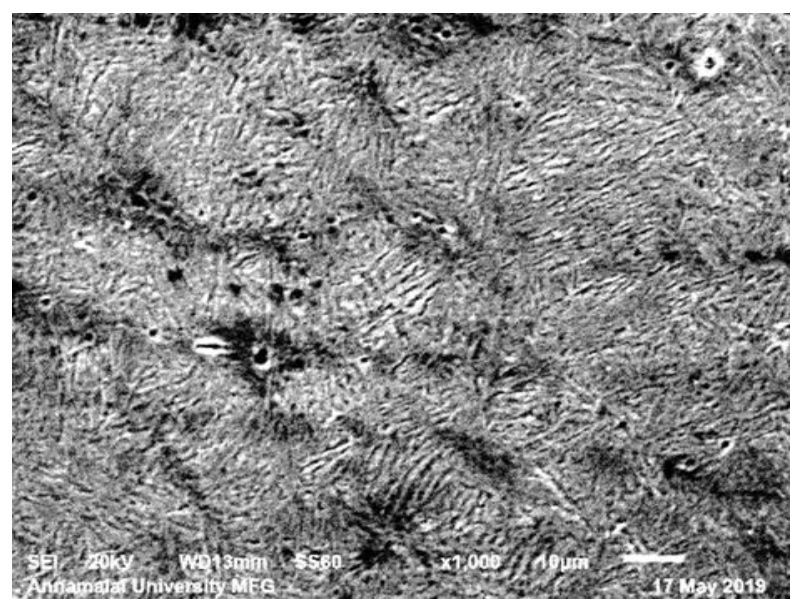

Figure 1 Scanning electron micrograph of base metal

After welding, the beads were flushed off and then sliced by wire electrical discharge machining (WEDM) process. Then the specimens were extracted to the rolling directions and dimensions are shown in Fig. 2 following ASTM E-08/8M16AE1 guidelines [10]. Two different tensile specimen configurations were used to evaluate the transverse tensile properties. They are: (i) The yield strength, tensile strength and elongation, were evaluated by smooth tensile specimen (ii) Notch tensile strength and notch strength ratio (NSR) were evaluated by notched tensile specimen (Fig 3). The universal testing machine of $1000 \mathrm{kN}$ (FIE-Bluestar Model: UNITEK-94100) was used for tensile test. The strain rate of $1.5 \mathrm{kN} \mathrm{min}-1$ was used for testing of tensile specimen so, the tensile specimen deforms uniformly in the gauge length region. Finally, the load versus displacement was recorded after specimen fail by necking. For yield strength $0.2 \%$ offset was used from the stress vs strain graph. The ductility parameters such as elongation percentage and area reduction were calculated from gauge length dimensions.

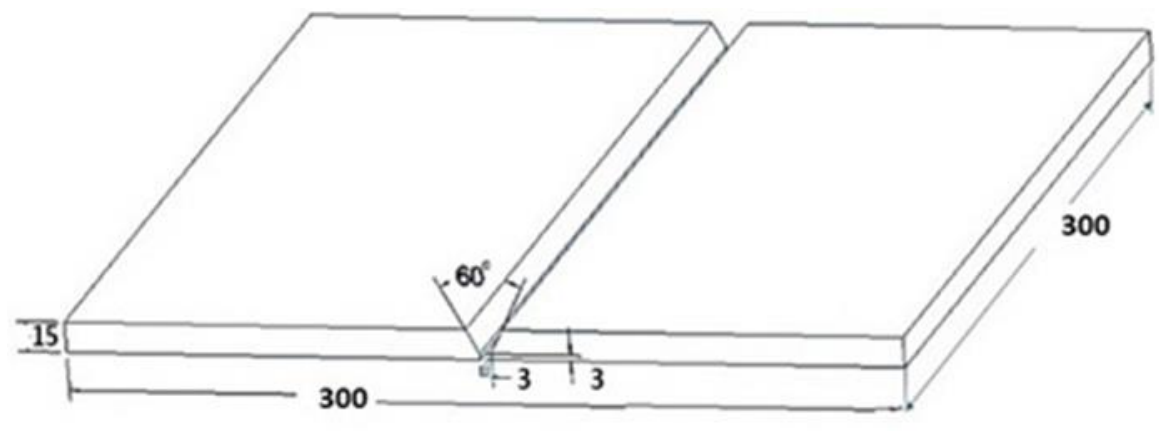

All Dimensions are in $\mathrm{mm}$

(a) Joint configuration

WELD DEPOSIT

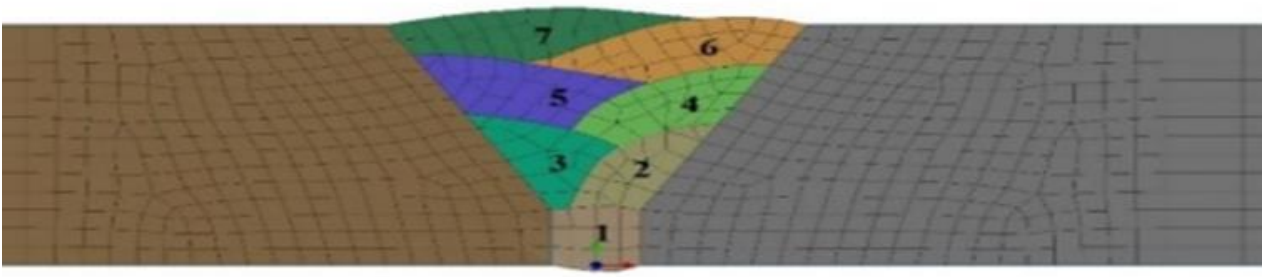

(b) Welding sequence 


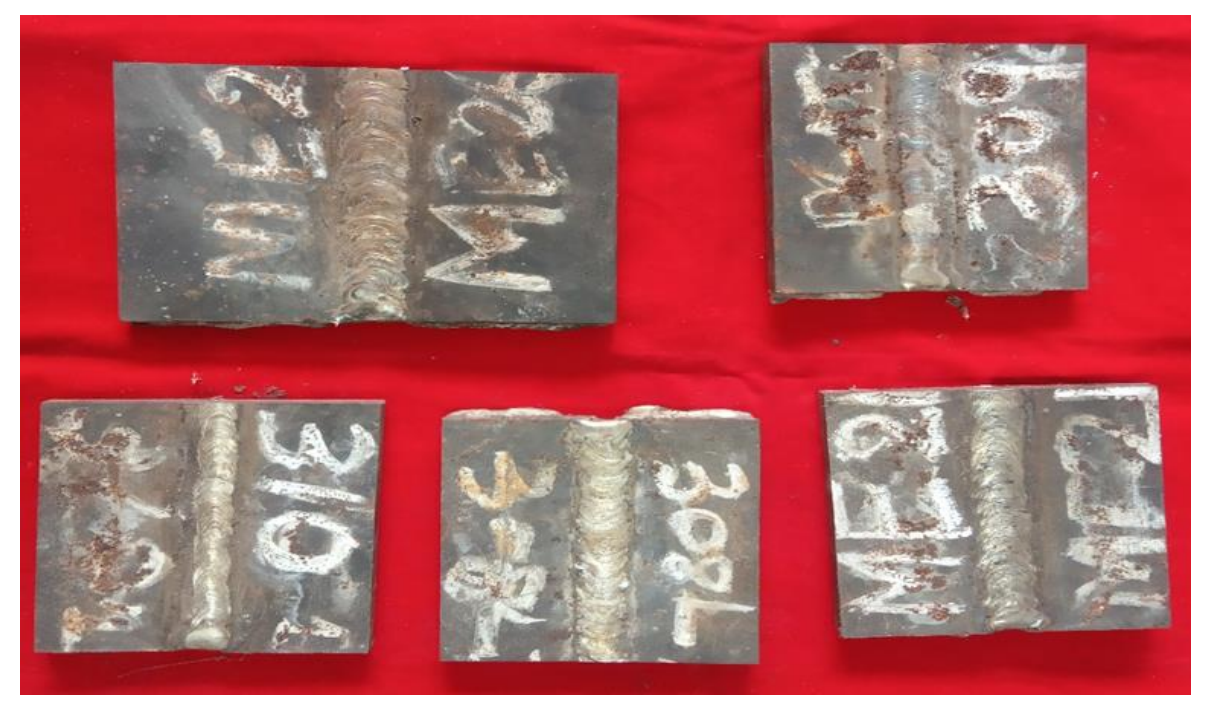

(c) Photograph of welded joints

Figure 2 Joint configuration and welding sequence used in this investigation

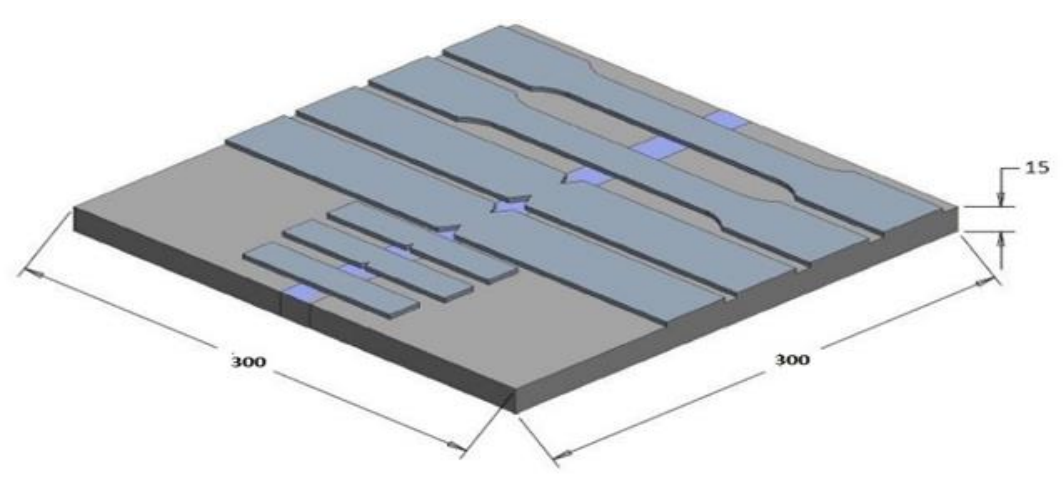

Note: All Dimensions are in $\mathrm{mm}$

(a) Scheme of specimen extraction from the welded joints

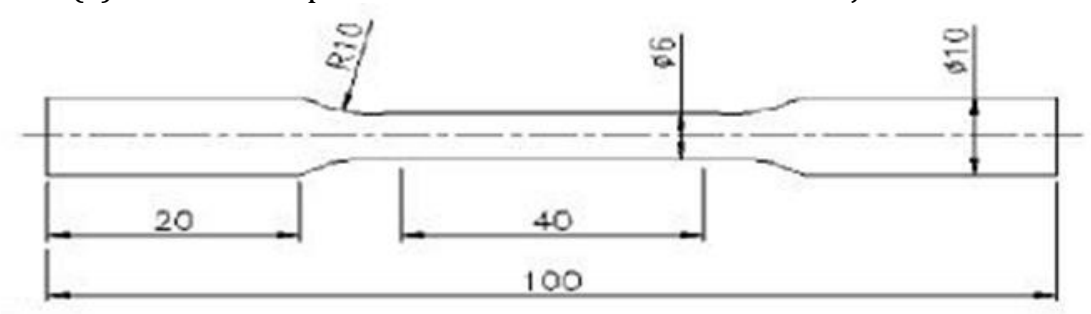

(b) Unnotched Tensile Specimen

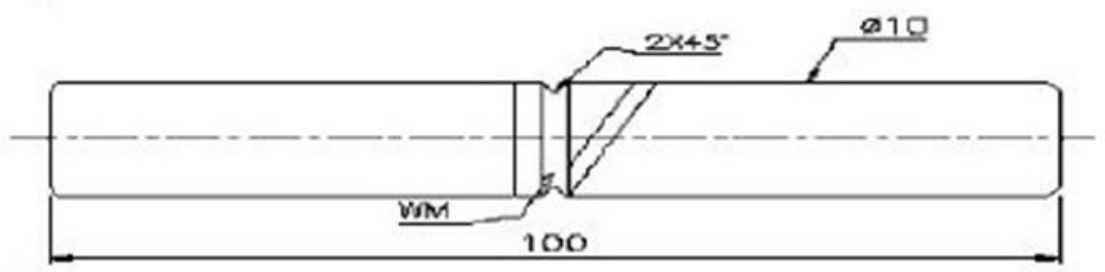

(c) Notched Tensile Specimen 


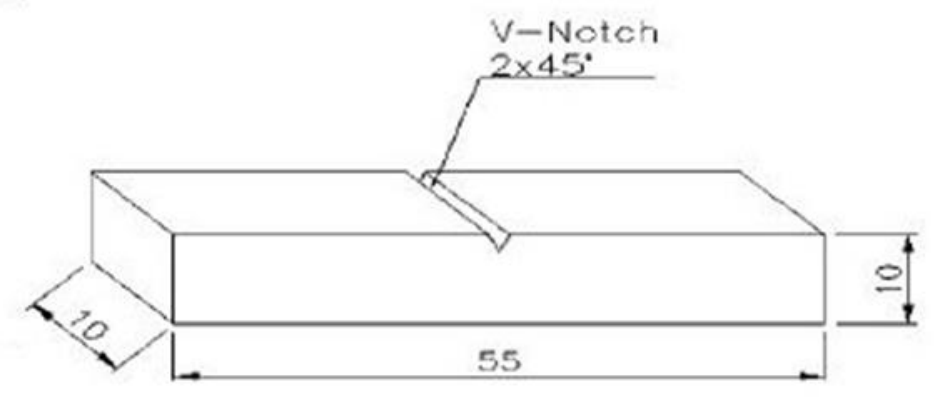

(d) Metallography Specimen

Figure 3 Scheme of extraction and specimen dimensions (in $\mathrm{mm}$ )

The microhardness (Make: Shimadzu; Model HMVT1) was measured across the weldment along the mid-thickness region using the load of $0.5 \mathrm{~kg}$ and dwell time of 15 seconds. The microstructure analysis of the weldment (Weld, HAZ, base metal) was done using the OM (Make: MEIJI, Model: ML7100). The two \% Nital solution was used to reveal HAZ and BM. Weld metal microstructure were revealed by Aqua regia. Delta ferrite (second phase) in the fusion zone was measured quantitatively using ferrite scope as (FN) following the standard procedures prescribed by AWS A 4.24- 74. The tensile specimens fractured surface was analyzed by the scanning electron microscope (Make: JEOL, Japan; Model: $5610 \mathrm{LV}$ ) to study the mode of failure.

\section{Results}

\subsection{Tensile properties}

The tensile properties of welded joints are shown in Table 4. The unnotched tensile specimen was used to evaluate tensile strength, yield strength and percentage elongation. Notch tensile strength and NSR were evaluated by testing notched tensile specimen. Two specimens were tested under each condition and the average of three is presented in Table 4. The photograph of tensile specimens is shown in Fig. 4. The fractured surface of the tensile tested specimens of BM and welded joints was analyzed using a scanning electron microscope and the fractographs taken are displayed in Fig. 5. The mode of failure in the BM and the joints are ductile with micro void coalescence in all cases. There is an appreciable difference in the size of the dimples with respect to the welded joints. It is evident from the fractographs of the BM that the dimples are finer than those in the welded joints. The fracture surface morphology of the ASS5 joint exhibits smaller dimples than ASS1, ASS2 and ASS4 joints. The dimple size exhibits a directly proportional relationship with the strength and ductility, i.e. if the dimple size is finer, then the strength and ductility of the respective joint is higher and vice ASS5 joint. From the tensile properties of welded joints, the following inferences were derived: (i) All tensile specimens failed at weld metal region only, irrespective of welding consumables; (ii) The ASS1 joint exhibited lowest tensile strength of $575 \mathrm{MPa}$, which is only $27 \%$ of BM strength.

Table 4 Transverse tensile properties of welded joints

\begin{tabular}{|c|c|c|c|c|c|c|c|}
\hline Joint & $\begin{array}{c}0.2 \% \text { Yield } \\
\text { strength } \\
\text { (MPa) }\end{array}$ & $\begin{array}{l}\text { Tensile } \\
\text { strengt } \\
\text { h (MPa) }\end{array}$ & $\begin{array}{c}\text { Elongation } \\
\text { in } 50 \mathrm{~mm} \\
\text { gauge length } \\
(\%)\end{array}$ & $\begin{array}{c}\text { Notch } \\
\text { Tensile } \\
\text { Strength } \\
\text { (MPa) }\end{array}$ & $\begin{array}{c}\text { Notch } \\
\text { Tensile } \\
\text { Ratio } \\
\text { (NSR) }\end{array}$ & $\begin{array}{c}\text { Joint } \\
\text { Efficiency } \\
(\%)\end{array}$ & $\begin{array}{c}\text { Location } \\
\text { of } \\
\text { Failure }\end{array}$ \\
\hline BM & 1450 & 2150 & 10 & 2215 & 1.03 & --- & -- \\
\hline ASS1 & 496 & 575 & 27 & 642 & 1.12 & 27 & WM \\
\hline ASS2 & 521 & 597 & 26 & 661 & 1.11 & 28 & WM \\
\hline ASS3 & 536 & 626 & 24 & 686 & 1.09 & 29 & WM \\
\hline ASS4 & 595 & 675 & 23 & 723 & 1.07 & 31 & WM \\
\hline ASS5 & 616 & 730 & 21 & 766 & 1.05 & 34 & WM \\
\hline
\end{tabular}




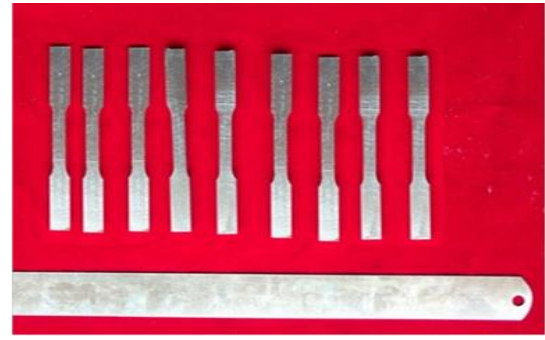

(a) Unnotched Tensile Specimen (before Testing)

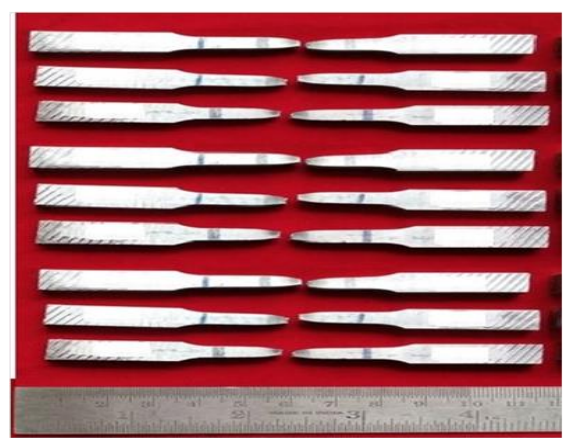

(c) Unnotched Tensile Specimen (aftor Testing)

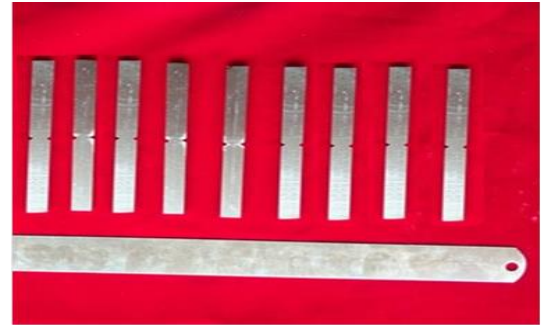

(b) Notched Tensile Specimen (before Testing)

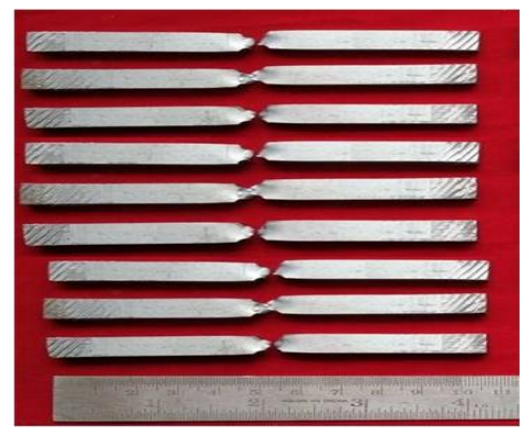

(d) Notched Tensile Specimen (after Testing)

Figure 4 Photographs of Tensile Test Specimen

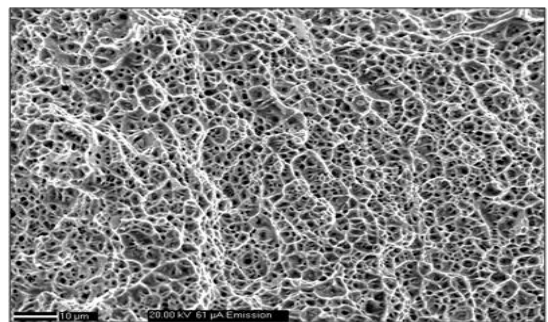

(a) Base Metal

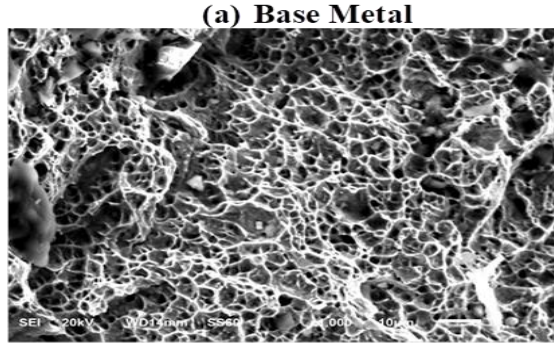

(c) ASS2 Joint

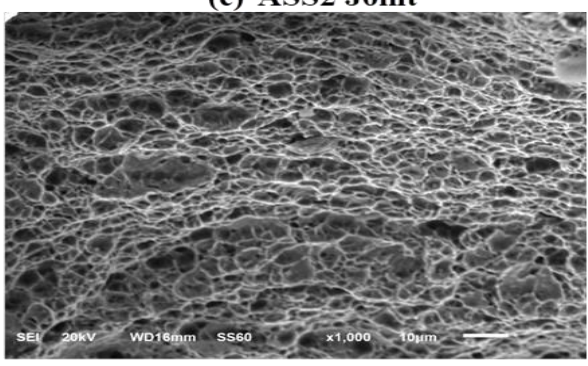

(e) ASS4 Joint

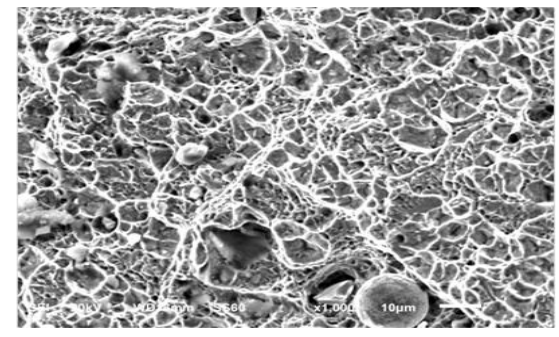

(b) ASS1 Joint

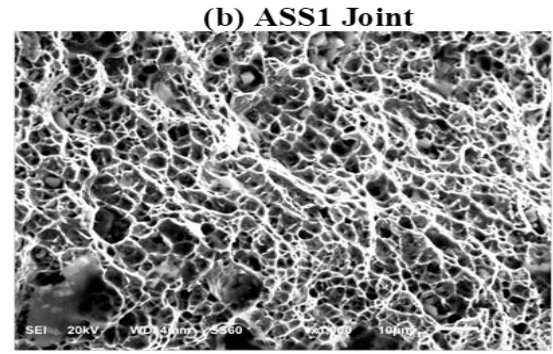

(d) ASS3 Joint

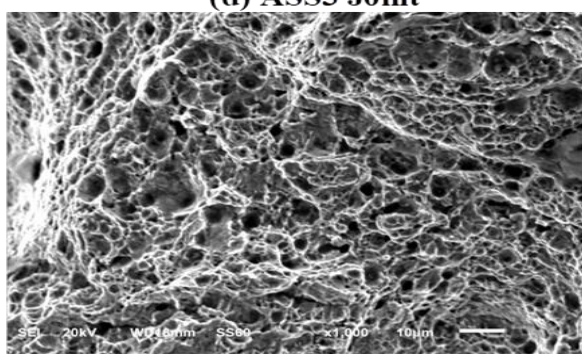

(f) ASS5 Joint

Figure 5 Fractured surface of tensile test specimen (unnotched) 
The ASS5 joint yielded highest UTS of $730 \mathrm{MPa}$ which is 34\% of BM strength; (iii) The ASS1 joint exhibited highest elongation (ductility) of $27 \%$, which is $17 \%$ higher than the BM elongation. The ASS1 joint yielded lowest elongation of $21 \%$ which is $11 \%$ higher than BM elongation; (iv) The ASS1 joint showed highest NSR (ductility parameter) of 1.12 which indicates the notch tensile strength (NTS) of these joints is $12 \%$ greater than the UTS of the joint. The ASS5 joint showed lowest NSR of 1.05 which indicates notch tensile strength (NTS) of these joints is 5\% greater than the UTS of the joints (v) in comparison, ASS1 joint showed superior ductility properties and ASS5 joint showed superior strength properties. From the tensile test results, it is known that all the specimens failed in the weld metal only, irrespective of welding electrodes used. It suggests that the WM region is weaker than the HAZ and base metal. However the significant variations in properties are observed. To understand the reasons for these marginal variations, fusion zone was characterized using microhardness measurement, microstructure analysis, chemical composition evaluation and volume of ferrite content quantification. The results are presented in following sections.

\subsection{Microstructure}

Microstructural analysis was performed at different region of the welded joints and it is known that weldments consist of three important regions (i) weld metal (WM), (ii) coarse grain heat-affected zone (CGHAZ) and (iii) fine grain heataffected zone (FGHAZ). Various regions of weldments captured using OM are picturized in Fig. 6. Figure 6a shows optical macrograph of weld cross-section and Fig. 6b shows the micrograph of the interface (WM and HAZ) of ASS5 joint. It reveals coarse untempered martensite towards HAZ from fusion line, and presence of type II boundary normal to fusion line towards the WM. These boundaries do not have any continuity and these boundaries are more prone to HIC than type I boundaries which are perpendicular to fusion line. While welding ferrite steel (base metal) using austenitic consumables, this sudden change of composition and microstructure across fusion line shows formation of martensitic band in fusion line [11]. In all the joints, very close to fusion line, the CGHAZ are observed (Fig. 6c - CGHAZ). These CGHAZ invariably of hardened region of untempered martensite in the joints. Away from the fusion line, towards the CGHAZ, the FGHAZ are observed (Fig. 6d - FGHAZ) in all the joints. CGHAZ reveal untempered martensite in the joints. Since the heat input during fabrication of joints remains same ( 0.9 to $1.0 \mathrm{~kJ} / \mathrm{mm})$, irrespective of welding consumables used, there is no appreciable variation observed in microstructure of CGHAZ and FGHAZ in all the joints.

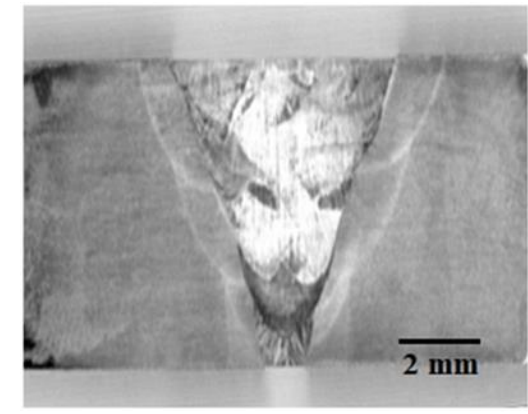

(a) Macrostructure

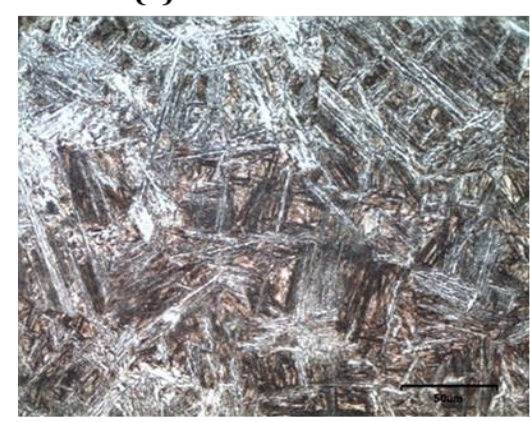

(c) CGHAZ

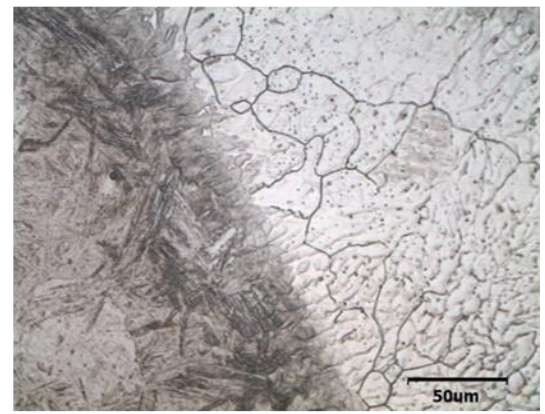

(b) WM-HAZ Interface

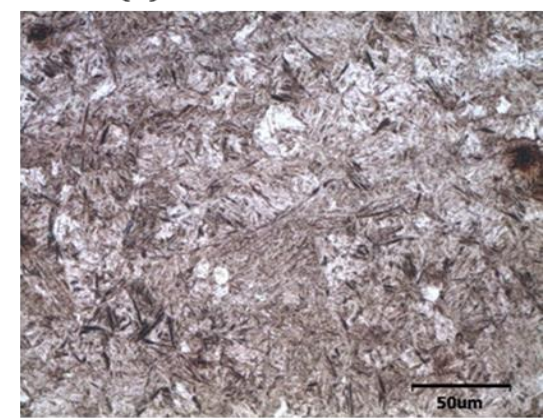

(d) FGHAZ

Figure 6 Optical micrographs of various regions of welded joint

The WM of the joints shows delta ferrite of different morphologies in the plain austenitic matrix (Fig. 7). However, delta ferrite can be differentiated as lathy or lacy, vermicular, acicular and globular morphologies. The WM of ASS1 joint consists of globular type delta ferrite in plain austenite matrix. The WM of ASS2 and ASS3 joints show vermicular type delta ferrite in the plain austenite matrix. The WM of ASS4 joint reveals lacy ferrite morphology in plain austenite matrix. However, the WM of ASS5 joint reveals a mixed morphology of both vermicular and globular delta ferrite in the plain austenite matrix. The evolution delta ferrite in the plain austenite matrix is primarily because of the presences of 
alloying component (Fe, $\mathrm{Cr}(18 \%)$ and $\mathrm{Ni}(8.01 \%))$. Since, $\mathrm{Fe}, \mathrm{Cr}$ and $\mathrm{Ni}$ have tendency to segregate in the intergranular and interdendritic locations and this produces columnar structure [12].

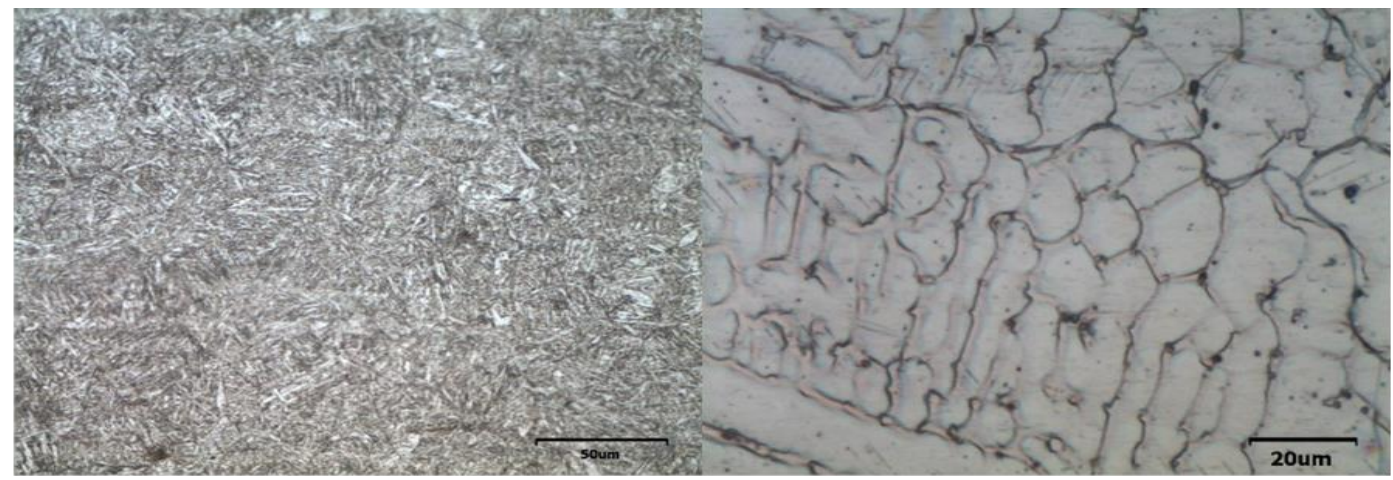

(a) Base Metal

(b) ASS1 Joint

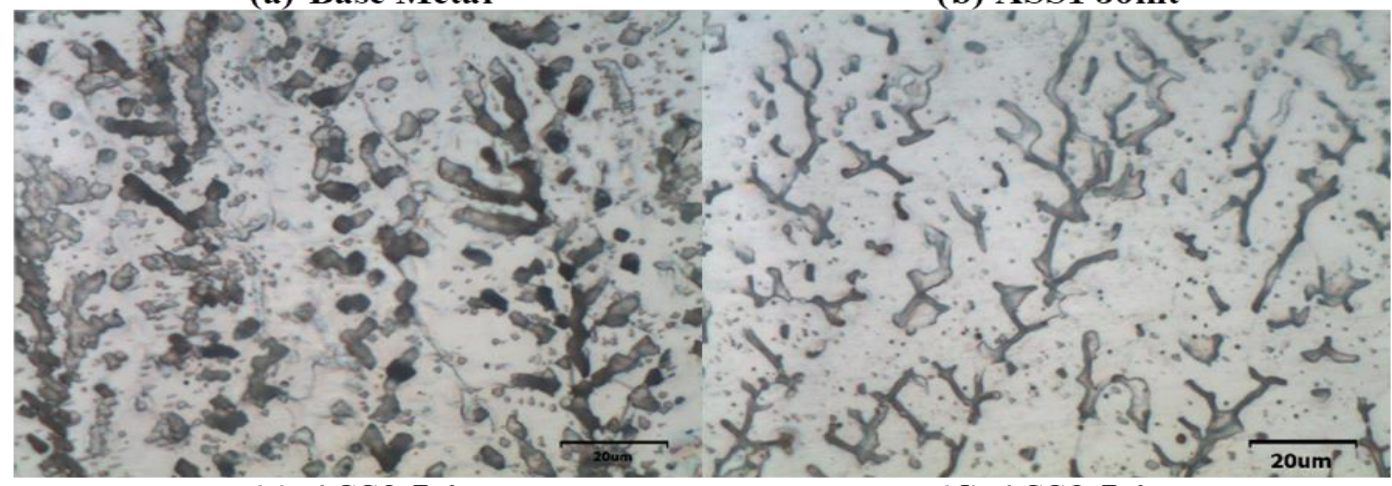

(c) ASS2 Joint

(d) ASS3 Joint

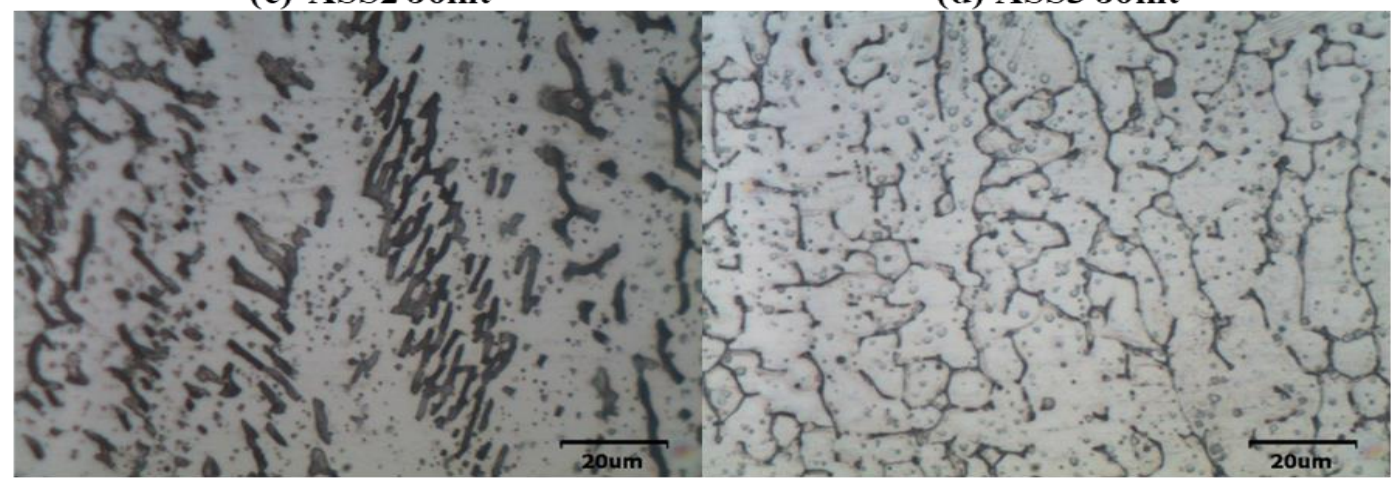

(e) ASS4 Joint

(f) ASS5 Joint

Figure 7 Optical micrographs of base metal and weld metal regions of welded joints

\subsection{Microhardness}

From the microstructure analysis, it is very clearly understood that weld joints having four different regions in transverse direction such as WM, CGHAZ, FGHAZ and BM. The hardness was measured at 10 different locations of each region and presented in Table 5 .

Table 5 Average Microhardness $\left(\mathrm{HV}_{0.5}\right)$ values of various regions of welded joints

\begin{tabular}{|c|c|c|c|c|}
\hline Joint & WM & CGHAZ & FGHAZ & BM \\
\hline ASS1 & 220 & 620 & 425 & 602 \\
\hline ASS2 & 230 & 630 & 430 & 602 \\
\hline ASS3 & 250 & 630 & 435 & 605 \\
\hline ASS4 & 280 & 635 & 440 & 606 \\
\hline ASS5 & 300 & 640 & 450 & 610 \\
\hline
\end{tabular}


From the microhardness results, following results can be derived: (i) The WM hardness is the lowest compared to all other regions, irrespective of welding electrode used; (ii) The hardness of FGHAZ is the highest compared to all other regions, irrespectively of welding electrode used; (iii) The hardness of CGHAZ is lower than FGHAZ and BM in all the joints and it suggests that CGHAZ has undergone softening due to thermal cycle; (iv) The ASS5 joint recorded highest WM hardness and ASS1 joint recorded lowest WM hardness; (v) The hardness variation is not enormous in both FGHAZ and CGHAZ and there was a marginal difference is observed in these regions; (vi) The hardness is varying between 620$640 \mathrm{HV}$ in FGHAZ and is varying between 425-450 HV in CGHAZ. The lowest hardness of WM is one of the reasons for the failure of all the joints at weld metal, irrespectively of welding electrodes used. However, the variations in WM composition has influence on WM hardness and subsequently on tensile properties joints.

\subsection{Weld Metal Composition}

The chemical composition of the weld metal (after welding) was also measured and is listed in Table 6. An appreciable change in composition was understood in WM (Table 6) compared to the all WM composition (Table 1) and this is mainly because of dilution of BM in weld metal due to welding. Weld metal compositions presented in Table 6 was utilized to compute the Chromium equivalent and $\left(\mathrm{Cr}_{\mathrm{eq}}\right)$ and Nickel equivalent $\left(\mathrm{Ni}_{\mathrm{eq}}\right)$ of diluted weld metal using following expressions [13] and shown in Table 7.

$\mathrm{Cr}_{\text {eq }}=\mathrm{Cr} \%+\mathrm{Mo} \%+0.7 \mathrm{X} \mathrm{Nb} \%$

$\mathrm{Ni}_{\text {eq }}=\mathrm{Ni} \%+35 \times \mathrm{C} \%+20 \times \mathrm{N} \%+0.25 \times \mathrm{Cu} \%$

Ferrite Number (FN) of the weld metal was measured using ferrite-scope and presented in Table 7. It provides an information about the amount of delta ferrite present in the diluted weld metal. From the Ferrite Number results, following inferences can be derived: (i) The ratio between $\mathrm{Cr}_{\text {eq }}$ and $\mathrm{Ni}_{\text {eq }}$ is having directly proportional relationship with the Ferrite Number, i.e., if the $\mathrm{Cr}_{\text {eq }} / \mathrm{Ni}_{\text {eq }}$ of weld metal is lower, then the weld metal will have lower ferrite number and vice versa; (ii) ASS1 joint recorded the lowest Ferrite Number compared to all other joints due to lower $\mathrm{Cr}_{\mathrm{eq}} / \mathrm{Ni}$ eq value; (iii) ASS5 joint recorded the highest Ferrite Number compared to all other joints due to higher $\mathrm{Cr}_{\text {eq }} / \mathrm{Ni}_{\text {eq }}$ value.

Table 6 Chemical composition (wt \%) of diluted weld metals (after welding)

\begin{tabular}{|l|l|l|l|l|l|l|l|l|l|l|}
\hline Joint & $\mathbf{C}$ & $\mathbf{S i}$ & $\mathbf{M n}$ & $\mathbf{C r}$ & $\mathbf{M o}$ & $\mathbf{N i}$ & $\mathbf{P}$ & $\mathbf{S}$ & $\mathbf{C u}$ & $\mathbf{F e}$ \\
\hline ASS1 & 0.113 & 0.576 & 2.20 & 25.33 & 0.131 & 18.36 & 0.031 & 0.012 & 0.183 & Bal \\
\hline ASS2 & 0.070 & 0.537 & 5.91 & 16.98 & 0.215 & 9.03 & 0.027 & 0.004 & 0.211 & Bal \\
\hline ASS3 & 0.086 & 0.622 & 1.53 & 20.05 & 0.155 & 11.06 & 0.024 & 0.007 & 0.126 & Bal \\
\hline ASS4 & 0.063 & 0.775 & 1.10 & 17.11 & 0.038 & 8.25 & 0.025 & 0.008 & 0.039 & Bal \\
\hline ASS5 & 0.100 & 0.571 & 1.52 & 18.02 & 2.03 & 8.01 & 0.026 & 0.010 & 0.248 & Bal \\
\hline
\end{tabular}

Table $7 \mathrm{Cr}_{\text {eq }}$ and $\mathrm{Ni}_{\text {eq }}$ values and Ferrite Number of Diluted Weld Metals (after welding)

\begin{tabular}{|l|l|l|l|l|}
\hline Joint Notation & Creq & Nieq & Creq/Nieq & Ferrite Number \\
\hline ASS1 & 26.325 & 22.850 & 1.15 & 1 \\
\hline ASS2 & 18.005 & 14.085 & 1.28 & 3 \\
\hline ASS3 & 21.138 & 14.405 & 1.47 & 9 \\
\hline ASS4 & 18.310 & 10.690 & 1.71 & 13 \\
\hline ASS5 & 20.906 & 11.770 & 1.78 & 26 \\
\hline
\end{tabular}




\section{Discussion}

\subsection{Effect of $\mathrm{Cr}$ eq/Ni eq on weld metal microstructure}

The occurrence of ferrite microstructure in weld metal gives a both of strength and ductility. This ferrite structure is very much desirable in all the welded structures as they have relatively higher hardness and strength. The tendency for the steel to solidification crack during cooling reduces by Ferrite [14-15]. It was described that cracks initiate preferentially along with the austenite- delta ferrite interface and high delta ferrite leads to the elongation loss [16].The ASS5 joint exhibits greater tensile properties due to the presence of greater volume fraction of delta ferrite in the austenitic matrix of the WM compared to other joints.

In a typical multilayer SMAW process for the joining of UHA steels with the aid of ASS electrodes, the constituent of the fusion zone is the primary contributor that determines the solidification mode as well as the microstructure in the weld metal. The nucleation and retention of $\delta$-ferrite in the inter-dendrite region of austenite are affected by the inter-pass temperature, heat input and the welding speed. The solidus and solves line in the Fe-Cr-Ni system that is mostly controlled by the $\mathrm{Ni}$ and $\mathrm{Cr}$ diffusion. The $\mathrm{Cr}_{\mathrm{eq}} / \mathrm{Ni}_{\text {eq }}$ plays a significant role in the solidification mode (fully A mode, $\mathrm{FA}$ mode, F mode) which determines the final microstructure of the weld metal [17].

Hence, if the $\mathrm{Cr}_{\mathrm{eq}} / \mathrm{Ni}_{\text {eq }}$ ratio is very less (1.1 to 1.2 ) then the tendency of hot cracking in the weld metal is significantly more. The microstructure of the ASS1 joint fabricated using AWS E-310electrode shows a fine crack in the weld metal which is attributed to lower $\mathrm{Cr}_{\mathrm{eq}} / \mathrm{Ni}_{\text {eq }}$ ratio. A small amount of delta ferrite (globular shape grain boundary) doesn't pin the MGB into sinuous. Sinuous pattern (Vermicular, Lacy) occurs in the other joints fabricated, which result in pinning of MGB. Therefore, the use of electrodes with lower $\mathrm{Cr}_{\text {eq }} / \mathrm{Ni}_{\text {eq }}$ ratio has to be strictly avoided to obtain sound weld joints.

From the microstructure analysis (Fig. 7), three different ferrite morphologies have been identified in the weld metal region such as vermicular, lacy, and globular. The composition of the weld metal expressed as a ratio of chromium to nickel equivalents $\left(\mathrm{Cr}_{\text {eq }} / \mathrm{Ni}_{\mathrm{eq}}\right)$ is one of the major factors determining the ferrite content in the weld metal [18]. Vermicular ferrite morphology was detected in weld metal deposited using ASS consumables having lower level of $\mathrm{Cr}_{\text {eq }} / \mathrm{Ni}_{\text {eq, }}$ i.e. 1.1 to 1.4 (ASS1 and ASS2 joints). Lacy ferrite morphology was detected in weld metal deposited using ASS consumables having medium level of $\mathrm{Cr}_{\text {eq }} / \mathrm{Ni}_{\text {eq }}$, i.e., 1.4 to 1.7 (ASS3 and ASS4 joints). Globular morphology was observed in weld metal deposited using ASS consumables having higher level of $\mathrm{Cr}_{\text {eq }} / \mathrm{Ni}_{\text {eq, }}$ i.e 1.7 and above (ASS5 joint).

The dilution of $\mathrm{Cr}$ from the base metal to weld metal changes the weld metal composition due to which ferrite number changes in the weld metal. If the $\mathrm{Cr}$ is greater than $17-18 \mathrm{wt} \%$, there is more susceptibility for the evolvement of sigma phase $\left(\mathrm{Fe}_{2} \mathrm{Cr}\right)$ which is a $\mathrm{Cr}$ rich phase. Since this phase is harder and brittle, it significantly reduces the ductility and toughness. The increase in ferrite number is maintained by increase in $\mathrm{Cr}_{\text {eq }}$ since $\mathrm{Cr}$ is a ferrite stabilizer. Hence, as the $\mathrm{Cr}_{\text {eq }} / \mathrm{Ni}_{\text {eq }}$ increases, there is an increase in the weld metal hardness. The ASS5 joint fabricated using AWS E307-26 (special grade) shows higher weld metal hardness and this may be due to higher $\mathrm{Cr}$ eq/ $\mathrm{Nieq}_{\text {eq }}$ compared to the other joints.

\subsection{Effect of $\mathrm{Cr}$ eq/ $/ \mathrm{Ni}_{\text {eq }}$ on Tensile Properties}

From the tensile properties results, it is clear that the strength properties (yield strength, tensile strength and notch tensile strength) of welded joints are inferior to that of unwelded base metal. This is mainly associated with the usage of under matching (strength) welding electrodes (ASS) to make the welded joints for avoiding hydrogen induced cracking. The ductility properties (percentage of elongation and notch strength ratio) of welded joints are superior to that of unwedded base metal. This is also mainly associated with the usage of over matching (ductility) welding electrodes (ASS). Though the ductility of welded joints is superior to the base metal, the strength of welded joints is inferior to the base metal, irrespective of welding consumables employed to make the joints. However, ASS5 joints revealed higher strength than other joints and ASS1 joint exhibited higher ductility than other joints. These differences in tensile properties of welded joints are principally controlled by the diluted weld metal elemental composition, i.e. $\mathrm{Cr}_{\text {eq }}$ and $\mathrm{Ni}_{\text {eq }}$ values as discussed in the section (4.1).

In this investigation, an effort has been made to relate the tensile properties of welded joints with the $\mathrm{Cr}_{\text {eq }} / \mathrm{Ni}_{\text {eq }}$ ratio of diluted weld metal as displayed in Fig. 8. From the graphs, it is inferred that the tensile strength (TS), notch tensile strength (NTS) and weld metal hardness (WMH) of welded UHA steel joints are having directly proportional relationship with the $\mathrm{Cr}_{\text {eq }} / \mathrm{Ni}_{\text {eq }}$ ratio of diluted weld metal, i.e., if the $\mathrm{Cr}$ eq $/ \mathrm{Nieq}$ ratio of the diluted weld metal is higher, then the welded joint exhibits higher strength and weld metal hardness and vice versa. However, the ductility (percentage of elongation, EL) of the welded UHA steel joints extends inverse proportionality with the $\mathrm{Cr}$ eq $/ \mathrm{Ni}_{\text {eq }}$ ratio of diluted weld metal, i.e., if the $\mathrm{Cr}_{\mathrm{eq}} / \mathrm{Ni}_{\text {eq }}$ ratio of the diluted weld metal is higher, then the welded joint will show lower 
ductility and vice versa. In Fig. 8, the data points are joined with a straight line by best fit line method. These straight lines are governed by following linear equations.

$\mathrm{TS}=\left\{224\left(\mathrm{Cr}_{\mathrm{eq}} / \mathrm{Ni}_{\mathrm{eq}}\right)+310\right\} \mathrm{MPa}$

$\mathrm{NTS}=\left\{178\left(\mathrm{Cr}_{\mathrm{eq}} / \mathrm{Ni}_{\mathrm{eq}}\right)+431\right\} \mathrm{MPa}$

$\mathrm{EL}=\left\{-8.63\left(\mathrm{Cr}_{\mathrm{eq}} / \mathrm{Ni}_{\mathrm{eq}}\right)+36.95\right\} \%$

$\mathrm{WMH}=\left\{123\left(\mathrm{Cr}_{\mathrm{eq}} / \mathrm{Ni}_{\mathrm{eq}}\right)+74\right\} \mathrm{HV} 0.5$

These equations can be effectively used to predict the tensile properties and weld metal hardness of the UHA steel joints welded using ASS consumables, if $\mathrm{Cr}_{\text {eq }} / \mathrm{Ni}_{\text {eq }}$ ratio of the diluted weld metal is known at $95 \%$ confidence level.

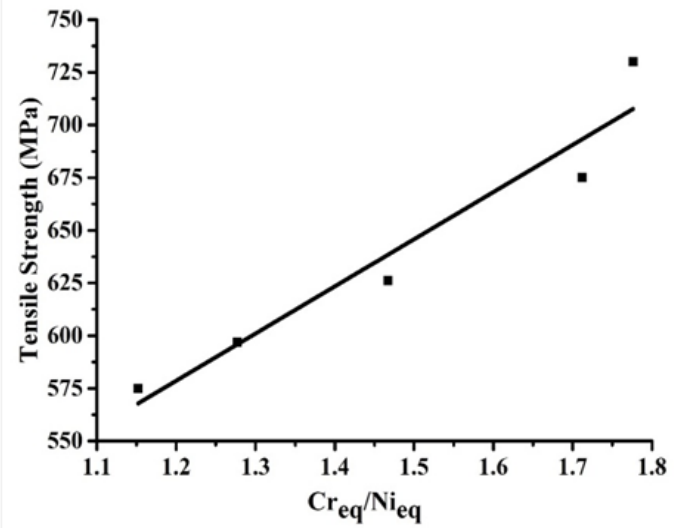

(a) Tensile Strength

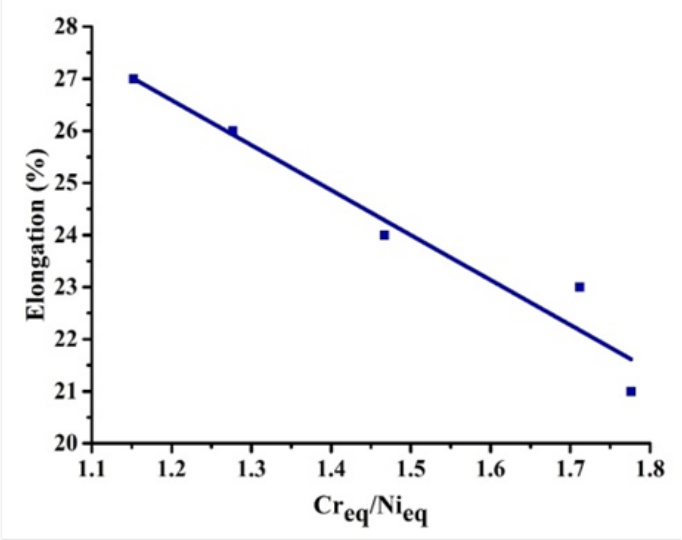

(c) Elongation

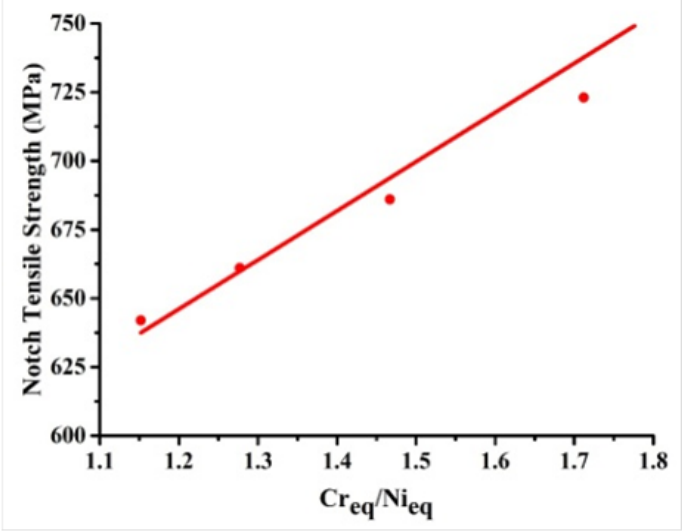

(b) Notch Tensile Strength

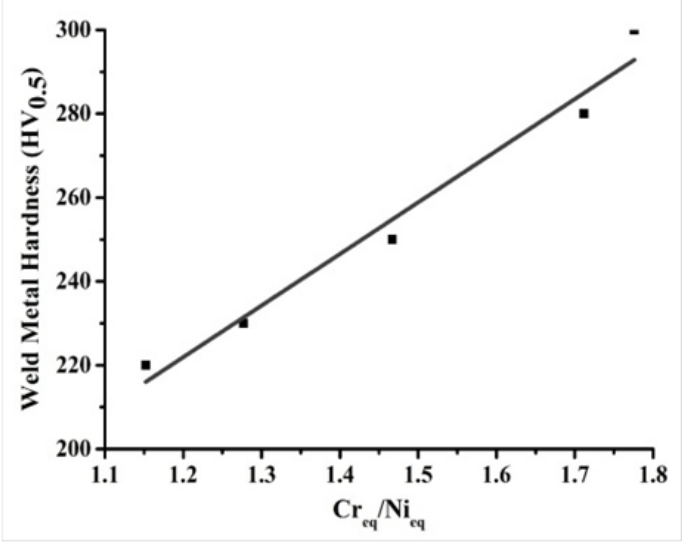

(d) Weld metal hardness

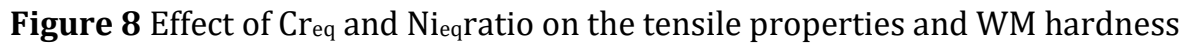

\section{Conclusion}

- Of the five ASS consumables used to weld UHA steel plates by SMAW process, the ASS5 joint (fabricated using E307-26, a special grade electrode) exhibited superior strength properties than other joints. This may be associated with the combined effect of formation of vermicular and globular ferrites and the evolvement of higher volume fraction of ferrite in weld metal region.

- Though the ASS1 joint (fabricated using E310-16 electrode) exhibited greater ductility (higher percentage of elongation and NSR) than other joints, the strength of the joints is very low. This may be associated with the appearance of finer cracks in the weld metal which is attributed to presence of lower volume fraction of ferrite. 
- The tensile strength (TS), notch tensile strength (NTS) and weld metal hardness (WMH) of welded UHA steel joints revealed directly proportional relationship with the $\mathrm{Cr}_{\text {eq }} / \mathrm{Ni}_{\text {eq }}$ ratio of diluted weld metal but the ductility (elongation) showed inversely proportional relationship.

\section{Compliance with ethical standards}

\section{Acknowledgments}

The authors record sincere thanks to the Directorate of Extramural Research \& Intellectual Property Rights (ERIPR), Defence Research \& Development Organisation (DRDO), Ministry of Defence, Government of India, New Delhi and Research Innovation Centre (RIC), DRDO, Chennai for the financial support rendered through a R\&D project no: EPIR/EP/RIC/2016/1/M/01/1630. The authors are grateful to the Director, Combat Vehicles Research \& Development Establishment (CVRDE), DRDO, Avadi, Chennai for providing base materials to carry out this investigation.

\section{Disclosure of conflict of interest}

The authors declare that they have no known conflict of interest.

\section{References}

[1] Paul K, Markku P, Ramio S, Jukka M. (2014). Welding of Ultra High Strength Steels. Advance Materials Research,849, 357-365.

[2] Magudeeswarana G, Balasubramanian V, Madhusudhan Reddy G. (2014). Effect of welding processes and consumables on fatigue crack growth behaviour of armour grade quenched and tempered steel joints. Defence Technology, 10(1), 47-59.

[3] Deb P, Challenger KD, Clark DR. (1988). Transmission Electron Microscopy Characterizations of Preheated and Non-Preheated Shielded Metal Arc Weldments of HY-80 Steel. Material Science Engineering A,77, 155-167

[4] Madhusudhan Reddy G, Mohandas T, Tagore GRN. (1995). Weldability Studies on High-Strength Low-Alloy Steel Using Austenitic Stainless Steel Filler. Journal of Material Processing and Technology, 49(1-2), 213-228

[5] Madhusudhan Reddy G, Mohandas T, Sarma D.S. (2013) Cold cracking studies on low alloy steel weldments effect of filler metal composition. Science Technology of Welding and Joining, 8(6),407-414.

[6] Rao EJ, Guha B, Malakondaiaha B. (1997). Effect of welding process on fatigue crack growth behaviour of austenitic stainless steel welds in a low alloy (Q \& T) steel. Theoretical Application of Fracture Mechanics, 27(2),141-148.

[7] Magudeeswaran G, Balasubramanian V, Balasubramanian T, Madhusudhan Reddy G. (2008). Effect of welding consumables on tensile and impact properties of shielded metal arc welded high strength, quenched and tempered steel joints. Science and Technology of Welding and Joining, 13(2),97-105.

[8] Magudeeswaranan G, Balasubramanian V, Sathyanarayanan S. Madhusudhan Reddy G, Moitra A, Venugopal S, Sasikala G. (2010). Dynamic Fracture Toughness of Armour Grade Quenched and Tempered Steel Joints Fabricated Using Low Hydrogen Ferritic Fillers. Journal of Iron and Steel Research International, 17(5), 51-56.

[9] Magudeeswaran G, Balasubramanian V, Sathyanarayanan S, Madhusudhan Reddy G, Moitra A, Venugopal S, Sasikala G. (2009). Dynamic fracture toughness (JId) behavior of armor-grade Q\&T steel weldments: Effect of weld metal composition and microstructure. Metals and Materials International, 15(6), 1017-1026.

[10] Madhusudhan Reddy G, Mohandas T. (1996). Ballistic performance of high-strength low-alloy steel weldments. Journal of Materials Processing Technology. 57(1-2), 23-30.

[11] Verma J, Taiwade RV, Khatirkar RK, Kumar A. (2016). A Comparative Study on the Effect of Electrode on Microstructure and Mechanical Properties of Dissimilar Welds of 2205 Austeno-Ferritic and 316L Austenitic Stainless Steel. Materials Transaction, 57(4), 494-500.

[12] Vashishtha H, Taiwade RV, Khatirkar RK, Dhoble AS. (2016). Effect of austenitic fillers on microstructural and mechanical properties of ultra-low nickel austenitic stainless steel. Science and Technology of Welding and Joining, 21(4), 331-337. 
[13] David S A. (1981). Ferrite morphology and variations in ferrite content in austenitic stainless steel welds. Weld Research, Supplement to the Welding Journal, 63-71.

[14] Inoue H, Koseki T, Ohkita S, Fuji M. (2000). Formation mechanism of vermicular and lacy ferrite in austenitic stainless-steel weld metals. Science and Technology of Welding and Joining, (5), 385-396.

[15] Sathiya P, Kumar Mishra M, Soundararajan R, Shanmugarajan B. (2013). Shielding gas effect on weld characteristics in arc-augmented laser welding process of super austenitic stainless steel. Optical Laser Technology, (45), 46-55.

[16] Balakrishnan M, Balasubramanian V, Madhusudhan Reddy G. (2011). Microstructural Analysis of Ballistic Tests on Welded Armor Steel Joints. Metallurgical Microstructural Analysis, (2), 125-139.

[17] Razzak MA. (2011). Heat treatment and effects of $\mathrm{Cr}$ and Ni in low alloy steel. Bulletin of Materials Science, 34(7), 1439-1445.

[18] Lai CL. Lu WF, Huang JY. (2014). Effect of $\delta$-ferrite content on the stress corrosion cracking behavior of cast austenitic stainless steel in high-temperature water environment. Corrosion, 70(6), 591-597. 